MATEC Web of Conferences 3, 01068 (2013)

DOI: $10.1051 /$ matecconf $/ 20130301068$

(C) Owned by the authors, published by EDP Sciences, 2013

\title{
Experimental determination and prediction of liquid-solid equilibria for binary (methyl palimitate + naphthalene) mixture
}

\author{
M. Benziane ${ }^{1}$, K. Khimeche ${ }^{1}$, A. Dahmani ${ }^{2}$, and D. Trache ${ }^{1}$ \\ ${ }^{1}$ Ecole Militaire Polytechnique E.M.P, B.P 17 Bordj-El-Bahri, Alger, Algérie \\ ${ }^{2}$ Laboratoire de thermodynamique et modélisation moléculaire, Faculté de chimie, USTHB, B.P 32 El-Alia, 16111 Bab- \\ Ezzouar, Alger, Algérie
}

\begin{abstract}
Solid-liquid equilibria for binary mixtures of \{Methyl palmitate (1) + Naphthalene (2) $\}$ were measured using differential scanning calorimeter (DSC). Simple eutectic behaviours for this system are observed. The experimental results were correlated by means of the NRTL, Wilson, UNIQUAC and ideal models. The root-mean-square deviations of the solubility temperatures for all measured data vary from 0.5477 $\mathrm{K}$ (for UNIQUAC model) to $3.34 \mathrm{~K}$; the deviation depend on the model used. The best solubility correlation was obtained with UNIQUAC model and this observation confirms previous results.
\end{abstract}

\section{Introduction}

Biodiesel (alkyl esters of fatty acids), produced by transesterification process from renewable natural sources such as vegetable oils and animal fats [1-4], is becoming a promising alternative to fossil fuels. Biodiesel can be used blended with petrodiesel (paraffinic fuel) in any percentage without affecting the performance of most diesel equipments. Blending biodiesel with diesel retains many of the advantages of biodiesel while overcoming some of its limitations. It is observed that by blending biofuel with fossil fuels, the combustion efficiency is enhanced and a cost-reduction in the distribution system is obtained [5-7].

Phase equilibria of mixtures of heavy aromatics and high methyl esters will be of great importance in the exploitation, transport and storage of diesel/biodiesel mixtures.

This study is a continuation of research works on the thermodynamic properties of organic compounds present in diesel/biodiesel blends and phase equilibria of their mixtures [8, 9]. It concerns the experimental determination and modeling of solid-liquid equilibria (LSE) of the binary system: Methyl palmitate (1) + Naphthalene (2).

\section{Experimental}

The suppliers and the purities of the methyl ester fatty acids and aromatics are reported in Table 1. These compounds were used without any further purification. For each binary system, the samples were prepared as described in literature [10-12], by heating very slowly in a Pyrex glass cell near the melting temperature of the major component.
Through continuous stirring, the liquefied sample was quenched in liquid nitrogen, ground and powdered in a clean agate mortar and dried in a desiccator. The rapid cooling of molten samples ensured a uniform stearic concentration of components in the mixture and homogeneity of the final molecular alloy $[13,14]$.

Small amounts of solid (5 to 10$) \cdot 10^{-3} \mathrm{~g}$ were taken and sealed in an aluminium pan of the DSC 8000 Perkin Elmer. Prior to the analysis, the DSC was calibrated using high-purity indium $99.999 \%$ having a melting point $429.60 \mathrm{~K}$ and enthalpy of fusion $28.45 \mathrm{~J} \cdot \mathrm{g}^{-1}$. Data acquisition (enthalpies of fusion of the pure compounds and onsets of the solid + liquid equilibria temperatures) and processing were done with Perkin - Elmer's Pyris software. The endothermic peaks are optimised for the best localisation of the onset temperatures. The mass of the samples was determined with a precision $\pm 0.0002 \mathrm{~g}$ using a Mettler H31 balance. The uncertainties of mole fraction did not exceed \pm 0.0005 . The uncertainties of the measurements are estimated to be $\pm 0.10 \mathrm{~K}$ for the temperature and $\pm 0.35 \mathrm{~kJ} \cdot \mathrm{mol}^{-1}$ for the enthalpy of fusion.

The measurements were carried out at constant heating rate of $1 \mathrm{~K} \cdot \mathrm{min}^{-1}$ under nitrogen atmosphere $\left(20 \mathrm{~cm}^{3} \cdot \mathrm{min}\right.$ $\left.{ }^{1}\right)$. This scanning rate is low enough to approach the equilibrium measurement conditions.

Table 1. Sources and purities of compounds.

\begin{tabular}{lcc}
\hline Chemicals name & Source & Purity/mol\% \\
\hline Naphthalene & Merck & $99 \%$ \\
Methyl palmitate & Alpha aesar & $99 \%$ \\
\hline
\end{tabular}




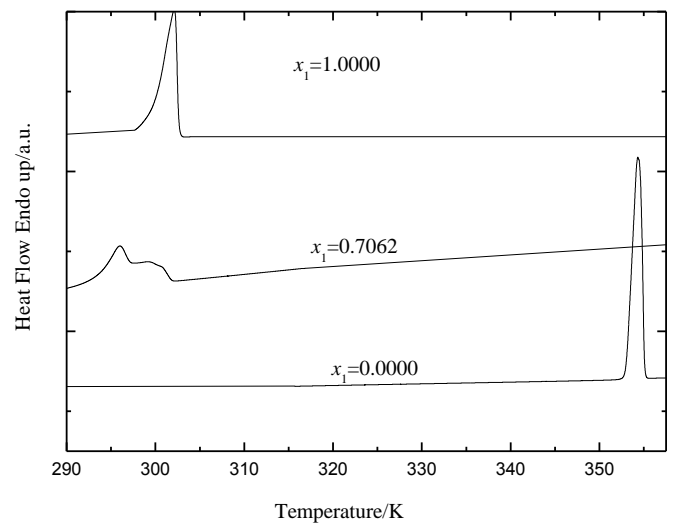

Figure 1. DSC thermogram for the one fraction of Methyl palmitate (1) + Naphthalene (2) binary mixture.

\section{Results and discussion}

\subsection{A. Determination of solid-liquid phase diagrams (SLPD)}

The melting points of the pure samples are globally in good agreement with literature data [11, 15-18]. Physical properties of pure compounds Tm (melting temperature) and $\Delta f u s H$ (molar enthalpy of fusion).

A typical DSC curve obtained for (Methyl palmitate (1) + Naphthalene (2)) mixture is shown in figure 1 .

The system show eutectic as the first peak appeared at a constant temperature. The area of the eutectic peak in a DSC curve is affected by the amount of the sample and the enthalpy of the melting of the component.

The eutectic composition is estimated by the intersection of the two curves of solubility by extrapolation and then localized with more precision by the determination of eutectic heat $\left(\Delta H_{\mathrm{eu}}\right)$ and the fusion heat $\left(\Delta H_{\mathrm{m}}\right)$. Plots of these heats versus mole fraction illustrate that eutectic corresponding for molar fractions 0.5983 and temperatures $305.24 \mathrm{~K}$.

\section{2 (Solid + liquid) equilibrium correlation}

SLE data can be used to calculate activity coefficients of the components. In the case of the studied systems, the components are not miscible in the solid phase and all diagrams present a simple eutectic. Therefore, the activity coefficient $\gamma \mathrm{i}$ of the component $\mathrm{i}$, in the liquid phase can be calculated according to the following expression [19]:

$$
\ln x_{i} \gamma_{i}=-\frac{\Delta \Delta_{f s} H_{i}}{R T} \cdot\left(1-\frac{T}{T_{\mathrm{m}, i}}\right)+\frac{\Delta C_{p, i}}{R}\left(\ln \frac{T}{T_{\mathrm{m}, i}}+\frac{T_{\mathrm{m}, i}}{T}-1\right)-\frac{\Delta H_{\mathrm{t}, i}}{R T}\left(1-\frac{T}{T_{\mathrm{t}, i}}\right)
$$

where $\Delta_{f u s} H_{\mathrm{i}}, T_{\mathrm{m}, \mathrm{i}}, \Delta \mathrm{C}_{\mathrm{p}, \mathrm{i}}, \Delta_{\mathrm{tr}} H_{\mathrm{i}}$ and $T_{t r, i}$ are respectively the molar enthalpy of fusion, the melting temperature, the molar heat capacity change (assumed to be independent of $\mathrm{T}$ ) during the fusion process, the enthalpy change corresponding to the transition and the transition temperature of the pure component i. As suggested by Prausnitz et al [19] the first term of eq.1 is dominant. The heat capacity term is generally small enough to be neglected compared with other terms. The modification of eq. 1 is similar to the approaches proposed by Coutinho et al [20], Domanska et al [21] and Cheng Pan et al [22]. In this study, the UNIQUAC [23], NRTL [24] and Wilson [25] models are used to derive the solute activity coefficients and predict SLE.

\section{Conclusion}

Solid-liquid phase equilibria for system of binary mixtures of aromatic and Fatty acids methyl ester have been studied by using DSC. The investigated binary system have simple eutectic.

The experimental results were correlated by means of the NRTL, Wilson, UNIQUAC and ideal models. These models are capable of predicting with satisfaction the SLPD for the binary system, the best solubility correlation was obtained with UNIQUAC model and this observation confirms previous results.

The data concerning the SLPD, principally the eutectic points of the studied system will be of great importance in the exploitation, transport and storage of diesel/biodiesel mixtures.

\section{References}

1. G. Antolin, F. Tinaut, Y. Briceno, Bioresource Technology 83111 (2002)

2. M.I. Al-Widyan, A.O. Al-Shyoukh, Bioresource Technology 85253 (2002)

3. G.M. Tashtoush, M.I. Al-Widyan, A.O. Al-Shyoukh, Energy Conversion and Management 452697 (2004)

4. S.K. Hoekman, A. Broch, C. Robbins, E. Ceniceros, M. Natarajan, Energy Reviews 16143 (2012)

5. T.L. Alleman, L. Fouts, R.L. McCormick, Fuel Processing Technology 921297 (2011)

6. A.V. Bueno, J.A. Velásquez, L.F. Milanez, Energy 36 3907 (2011)

7. Y.C. Lin, T.Y. Wu, W.C. Ou-Yang, C.B. Chen, Atmospheric Environment 432642 (2009)

8. M. Benziane, K. Khimeche, A. Dahmani, S. Nezar, D. Trache, Molecular Physics 1101383 (2012)

9. M. Benziane, K. Khimeche, I. Mokbel, T. Sawaya, A. Dahmani, J. Jose, J. Chem. Eng. Data 564736 (2011)

10. A. Mekki, K. Khimeche, A. Dahmani, J. Chem. Thermodyn. 421050 (2010)

11. K. Khimeche, A. Dahmani, J. Therm. Anal. Calorim. 8447 (2006)

12. K. Khimeche, A. Dahmani, J. Chem. Thermodyn. 38 1192 (2006)

13. V. Chevallier, D. Petitjean, V.R. Meray, M. Dirand, Polymer. 405953 (1999)

14. K. Khimeche, Y. Boumrah, M. Benziane, A. Dahmani, Thermochim. Acta 444165 (2006)

15. K. Benkhennouf, K. Khimeche, A. Dahmani, J. Phys. IV 1137 (2004)

16. C. Peng, H. Liu, Y. Hu, Fluid Phase Equilib. 180299 (2001)

17. G.J. Suppes, M.J. Goff, L. Shailesh, Chemical Engineering Science. 581751 (2003) 
18. J.S. Chickos, H. Zhao, G. Nichols, Thermochim. Acta 424111 (2004)

19. J.M. Praunitz, E.G. Lichtenthaler, E.G. Azevedo, Molecular Thermodynamics of Fluid Phase Equilibria, $2^{\text {nd }}$ ed, Prentice-Hall, 1986

20. J.A.M. Coutinho, S.I. Andersen, E.H. Stenby, Fluid Phase Equilib. 117138 (1996)

21. U. Domanska, F.R. Groves, E. Mc Laughlin, J. Chem. Eng. Data. 3888 (1993)

22. C. Pan, M. Radosz, Fluid Phase Equilib. 15557 (1999)

23. M. Mukhopadhyay, K. Sahasranaman, Ind. Eng. Chem. Process Des. Dev. 21632 (1982)

24. J. Nagata, Y. Nakamiya, K. Katoh, J. Koyabu, Thermochim. Acta. 45153 (1981)

25. G.M. Wilson, J. Am. Chem. Sot. 86127 (1964) 